Public Health Unit of the Institute of Health Sciences, Catholic University of Portugal

2 Centre for Population Health Sciences, Usher Institute, University of Edinburgh

3 Medical School and INCLIVA, University of Valencia, Spain

4 Wolverhampton University

5 Association of Schools of Public Health in the European Region (ASPHER)

Cite this as: BMJ 2022;376:0425 http://dx.doi.org/10.1136/bmi.0425 Published: 18 February 2022

\title{
Invest in primary healthcare and public health for the pandemic and beyond
}

\section{The covid-19 pandemic has made the need to invest in primary care even clearer, write Henrique Lopes and colleagues}

Henrique Lopes, ${ }^{1}$ Alison McCallum, ${ }^{2}$ Jose M Martin-Moreno, ${ }^{3}$ John Middleton ${ }^{4,5}$

Governments and health administrations need to invest more in primary healthcare. This has become increasingly apparent as the covid-19 pandemic has progressed and changed with the current omicron wave, but it is also an investment for a post-pandemic future. ${ }^{1-4}$

The pandemic hit hospitals hardest first, a reality which was particularly visible in the unprepared health systems of European countries. ${ }^{5}$ Yet covid-19 has also placed a number of stressors on primary healthcare. Primary healthcare committed early on to new models of working that were made necessary by lockdowns and which have accelerated the digital health revolution. ${ }^{1-3}$ Mass vaccination in 2021 in many countries demanded the proactive involvement of all sectors, especially primary care, public health, community services, and the third sector. 47 Inequalities in uptake of the vaccine could only be understood and overcome by community organisations that were sensitive to local needs and beliefs, alongside trusted primary care professionals. ${ }^{8}$

More recently, the omicron wave has been characterised by severe service disruption in key areas of the economy, brought about by sickness absence and uncontrolled infection in children. Many European governments have not followed a "vaccine plus" approach ${ }^{9}$ and have therefore failed to use all the preventive measures available to us to manage covid-19. ${ }^{10}$ Most covid restrictions have been removed, replaced only by often vague educational appeals to individual behaviours. ${ }^{11}$ The delta and omicron waves have seen increasing numbers of children and younger adults exposed to the virus, and rates of infection have not declined as much as anticipated, creating more burden for primary healthcare.

Evidence has so far suggested that the Omicron variant leads to less severe covid-19 disease than delta. ${ }^{12}$ Yet with such high case numbers in many European countries, this means that care will shift progressively from hospitals to primary healthcare, all without any accompanying plans in place to strengthen investment and reallocate staffing, as happened in hospitals during the first covid wave. As societies are open again while case rates remain high, primary care and community services remain fragile. $^{13}$

Meanwhile, the implications of long covid, mental exhaustion, and "pandemic fatigue" for population ill health and primary healthcare are coming into stark relief. ${ }^{14}$ With the majority of care out of hospital, new gaps in primary care, such as in school nursing and occupational and mental health, are being recognised.

There has never been a clearer need to invest in and plan for better integration of primary and community healthcare, alongside an expanded, better resourced, and appropriately trained multidisciplinary public health workforce. ${ }^{15}$

Local and national governments and health administrations should understand and act on the principle that preparedness and response begins with communities, public health, and primary care services. They should assume that everyone needs to be involved in the creation and dissemination of new knowledge and understanding to respond to the challenges posed by the pandemic: prevention, awareness, diagnosis, treatment, and recovery. Health and science literacy and forms of communication must be within the reach of all.

The core of our approach in responding to and recovering from covid-19 should be through investment into primary care, interconnected with spending on public health services. Primary healthcare needs to be sustainably strengthened with the necessary human, financial, and technological means, with the level of investment reflecting the level of community need. Universal community and homecare services are a vital adjunct to resilient primary healthcare, including support for carers.

Children have been particularly hard hit and neglected in the omicron wave. New investment should attend to the need for children's health being supported in the community, including school nursing, and health systems should ensure services are complementary to other primary care.

Local and national governments should invest in community development and community voluntary services that can support preventive efforts to tackle inequalities, support vulnerable people, and respond to needs caused by the pandemic. Health administrations should review the availability of occupational health services and seek to grow these to meet the healthcare needs of all workforces.

We know that primary healthcare is the main source of assessment and support for people with multimorbidity. Any new plans for strengthening primary care need to safeguard support for people who are chronically ill, ensure their better longitudinal and coordinated care, and minimise the likelihood of them receiving unconnected or non-integrated hospital services. Primary and community services should also be established and 
funded to manage the increase in multimorbidity that has arisen as a direct consequence of long covid and the worsening of pre-existing conditions, which has come about as an indirect consequence of the pandemic. ${ }^{14}$

The current pandemic response has produced significant amounts of non-recyclable waste. ${ }^{16}$ As we strengthen primary care and public and community health, we must build approaches that are more sustainable, less wasteful, and which give due attention to the protection of local and global ecosystems and the environment, in accordance with the "One Health" philosophy. ${ }^{17}$

Our global community is beset by threats to our health. We have taken our eye off antimicrobial resistance, a major killer. ${ }^{18}$ And we are failing to protect the world with equitable vaccine delivery. ${ }^{19}$ This pandemic will not be over until it is over for everyone. We must invest in local public health and primary care and their communities to get us out of this pandemic and to give us all better health for the future.

Competing interests: John Middleton is an elected, unpaid official of ASPHER, a membership organisation.

Provenance and peer review: not commissioned; not peer reviewed.

1 Royal College of General Practitioners. General practice in the post-COVID world. London. Royal College of General Practitioners, 2020. https://www.rcgp.org.uk/policy/general-practice-postcovid.aspx.

2 OECD Policy responses to coronavirus (COVID-19) Strengthening the frontline: how primary care helps health systems adapt during the pandemic. Paris. OECD. 2021

https://www.oecd.org/coronavirus/policy-responses/strengthening-the-frontline-how-primaryhealth-care-helps-health-systems-adapt-during-the-covid-19-pandemic-9a5ae6da/

3 Covid-19: Resources for general practitioners/family physicians. WONCA (World Family Doctors). https://www.woncaeurope.org/kb/covid-19-resources-for-general-practitioners-family-physicians

4 Mughal F, Mallen CD, McKee M. The impact of COVID-19 on primary care in Europe. Lancet Reg Health Eur 2021;6:100152. doi: 10.1016/j.lanepe.2021.100152. pmid: 34226894

5 Lopes $\mathrm{H}$, Middleton J. What should we ask of a new global treaty for pandemic preparedness? BMJ Opinion. 26 April 2021. https://blogs.bmj.com/bmj/2021/04/26/what-should-we-ask-of-anew-global-treaty-for-pandemic-preparedness/

6 Middleton J, Lopes H, Michelson K, Reid J. Planning for a second wave pandemic of COVID-19 and planning for winter : A statement from the Association of Schools of Public Health in the European Region. Int J Public Health 2020;65:1525-7. doi: 10.1007/s00038-020-01455-7. pmid: 32857238

7 Ritchie H, Mathieu E, Rodés-Guirao L, et al. Coronavirus (COVID-19) Vaccinations. https://ourworldindata.org/covid-vaccinations.

8 COVID-19: vaccination case studies. London. Local government association. 2022. https://www.local.gov.uk/our-support/coronavirus-council-information-and-support/covid-19good-council-practice/covid-19-0

9 Open letter from public health experts, scientists, and clinicians. Covid-19: An urgent call for global "vaccines-plus" action. BMJ2022;376:01. doi: 10.1136/bmj.01.

10 Middleton J, Lopes H. With covid-19, single measures aren't enough. BMJ2021;375:n3157 doi: 10.1136/bmj.n3157. pmid: 34965930

11 Middleton J. Is the NHS prepared for the coming winter? BMJ Opinion 9 September 2021. https://blogs.bmj.com/bmj/2021/09/09/john-middleton-is-the-nhs-prepared-for-the-comingwinter

12 World Health Organization. Update on SARS-CoV-2 variant of concern omicron. February 2022 https://cdn.who.int/media/docs/default-source/epi-win/webinar-report-epi-win/presentation_sylvie_briand.pdf?sfvrsn=f036d40a_5.

13 Taylor L. Covid-19: Omicron drives weekly record high in global infections. BMJ 2022;376:066. doi: 10.1136/bmj.066. pmid: 35017144

14 Lopes H, McCallum A, Martin-Moreno JM, Middleton J. ASPHER Statement: Invest in primary health care and public health for the pandemic and beyond Brussels: Association of schools of public health in the European region, February 2022. Available at: https://www.aspher.org/download/1026/invest-in-primary-health-care-and-public-health.pdf.

15 Middleton J, Biberman D, Magana L, etal. Global Governance for Improved Human, Animal, and Planetary Health: The Essential Role of Schools and Programs of Public Health. Public Health Rev 2021;42:1604610. doi: 10.3389/phrs.2021.1604610. pmid: 35140997

16 WHO. Global analysis of health care waste in the context of covid-19: status, impacts and recommendation. 1 February 2022. www.who.int/publications/i/item/9789240039612.

17 One Health Commission. What is One Health? Apex NC, 2022. https://www.onehealthcommission.org/en/why_one_health/what_is_one_health/.

18 Antimicrobial Resistance Collaborators. Global burden of bacterial antimicrobial resistance in 2019: a systematic analysis. Lancet 2022;399:629-55. doi: 10.1016/S0140-6736(21)02724-0. pmid: 35065702
19 World Federation of Public Health Associations. A vaccine TRIPS waiver now. Geneva: WFPHA, November 26th 2021. https://www.wfpha.org/a-vaccine-trips-waiver-now-letter-to-wto/ 